\title{
VIOLÊNCIA, DEMOCRACIA E ASSIMILAÇÃO NO TRATADO TEOLÓGICO-POLÍTICO DE ESPINOSA
}

\author{
VIOLENCE, DEMOCRACY AND ASSIMILATION IN THE THEOLOGICAL-POLITICAL TREATISE OF \\ SPINOZA
}

Andrelino Ferreira dos Santos Filho*

\section{RESUMO}

Trata-se de explicitar no Tratado teológico-político de Espinosa os elementos que possibilitam a demonstração da afirmação de que a democracia é o mais natural dos regimes políticos. Importa investigar, segundo a hipótese formulada a partir de Léo Strauss, se a tese da assimilação defendida por Espinosa como alternativa à recusa da concepção de nação eleita possui implicações antissemitas. Para tanto, é de importância cabal a compreensão do vínculo intrínseco entre o Apêndice da Parte I da Ética e o Tratado teológico-político, bem como do fundamento gnosiológico exposto no Tratado da reforma da inteligência e na Parte II da Ética acolhidos na exposição do direito natural desvelado no Tratado teológico-político.

PALAVRAS-CHAVE: Finalismo. Política. Direito natural. Antissemitismo. Violência.

\section{ABSTRACT}

This work aims at explaining in the Theological-Political Treatise which elements that make possible to demonstrate the assertion that democracy is the most natural of political regimes. It is necessary to investigate, according to the hypothesis formulated by Leo Strauss, if the thesis of the assimilation espoused by Espinosa as an alternative to the refusal of the concept of elect nation has anti-Semitic implications. In order to understand the intrinsic connection between the Appendix to Part I of Ethics and the Theological-political treatise, as well as the gnosiological foundation set forth in the On the improvement of the understanding and Part II of Ethics, which are set forth in the exposition of natural law as revealed in the Theologicalpolitical treatise.

KEYWORDS: Finalism. Politics. Natural law. Anti-semitism. Violence.

\section{INTRODUÇÃO}

O pensamento de Baruch Espinosa tem sido objeto de inúmeras controvérsias em relação a muitos temas, mas a tentativa de discutir no autor evidências de uma posição que sugere fomentar posturas antissemitas merece atenção especial. Essa atenção se deve não apenas pela fertilidade da questão, mas sobretudo pela importância do contexto a que ela se

\footnotetext{
* Doutor em Estudos Literários - FALE/UFMG; Doutorando em Filosofia - FAFICH/UFMG; Professor de Filosofia na PUC Minas e na UEMG. E-mail: andrelinofilho@yahoo.com.br. Texto apresentado no Simpósio Internacional 70 anos do fim da Segunda Guerra Mundial (FFLCH /USP) e, sob nova perspectiva, no Simpósio filosófico: violência, discurso e poder, realizado na PUC Minas (2017) sob o título de Política e violência em Espinosa.
} 
destinou, a saber, o Simpósio Internacional 70 anos da Segunda Guerra Mundial realizado em 2015 na USP.

De fato, a imagem de Espinosa como o solitário polidor de lentes dificilmente se sustenta em face da vivacidade na qual se expressa o interesse por sua obra imediatamente à sua produção, como a vasta correspondência o demonstra. Em que pesem as perseguições sofridas pelo filósofo, as quais poderiam sugerir como consequência o isolamento do pensador, Espinosa esteve atentamente envolvido nos acontecimentos de sua época.

A época de Espinosa, na especificidade da Holanda, é por ele mesmo referido como um momento marcado pela felicidade de desfrutar da liberdade de pensar. Nas palavras do filósofo:

\begin{abstract}
E já nos coube em sorte essa rara felicidade de viver numa República, onde se concede, a cada um, inteira liberdade de pensar e de honrar a Deus como the aprouver e onde não há mais nada de estimado nem mais agradável do que a liberdade, pareceu-me que não seria tarefa ingrata ou inútil mostrar que essa liberdade não só é compatível com a piedade e a paz social, como, inclusive, não pode ser abolida sem se abolir, ao mesmo tempo, a paz social e a piedade. Foi sobretudo isso o que decidi demonstrar neste tratado. Para tanto, foi necessário, antes de mais nada, apontar os maiores preconceitos em matéria religiosa, isto é, os vestígios da antiga servidão, bem como aqueles que se referem ao direito das autoridades soberanas, direito que muitos se esforçam, com descarado atrevimento, por lhes usurpar em boa parte, tentando, a pretexto da religião, pôr contra elas o ânimo das multidões, submetido ainda à superstição dos gentios, para que todos caiam de novo na servidão. Direi a seguir, em breves palavras, qual a ordem por que são apresentados os assuntos; mas antes vou expor as razões que me levaram a escrever. (ESPINOSA, 2008, p. 9).
\end{abstract}

A questão é, como alerta Aurélio nas notas introdutórias ao Tratado teológico-político, "se a Bíblia é a principal fonte de legitimação do poder, e, se o poder se destina a garantir a segurança e a paz entre os indivíduos, há que explicar por que razão estes se combatem em nome da mesma Bíblia, tornando assim ineficaz a suposta legitimação" (AURÉLIO, 2008, p. XIII).

Nas cartas destinadas a Oldenburg - XXIX e XXX -, por exemplo, o filósofo aparece plenamente integrado às discussões intelectuais da época (ESPINOSA, 1979d). Mas enfatizar a correspondência de Espinosa não basta para indicar a força de seu pensamento, na medida em que o interesse pelo filósofo poderia esgotar-se na imediatidade de seus interlocutores. É importante destacar que a filosofia espinosana, desde o século XVII, tem sido objeto de uma candente atividade teórica que, certamente, o coloca em um indiscutível lugar canônico. Ainda assim, por vezes, o estatuto de sua filosofia sofreu, especialmente na primeira metade 
do século XX, diversas investidas críticas na tentativa de desqualificá-lo pela pretensa filiação ou mesmo expressão do pensamento judaico.

Nesse sentido, destaca-se o artigo de Manfred Walther (2013), que analisa a disputa por Espinosa na Alemanha entre o final do século XIX e o fim do Terceiro Reich. A análise consiste em mostrar a incongruência da presença de filósofo de origem judia na cultura alemã. Para tanto, parte-se da habilitação do espinosismo como exemplo paradigmático da emancipação do judaísmo à desqualificação de sua filosofia pela destituição de qualquer originalidade ou pela assumida acusação antissemita de que "uma vez judeu sempre judeu"; o tratamento dado por Espinosa aos judeus parece o critério decisivo nessa disputa.

O tema da assimilação como o caminho oferecido aos judeus em face ao sonho sionista remete diretamente ao Tratado teológico-político de Espinosa, nutrindo a vivacidade da obra em face da força que a problemática do antissemitismo possui ainda hoje. É o que, por exemplo, indica o artigo de Bila Sorj (2007). Para a socióloga, nas sociedades europeias atuais, as identidades coletivas fundadas na figura dos estados nacionais não mais dão conta de conferir sentido aos indivíduos, de modo que a Europa vem assistindo à irrupção de uma profusão de identidades coletivas baseadas em elementos religiosos, étnicos e diaspóricos. Nesse cenário, seria pouco intuitivo não imaginar a existência - para não dizer aumento - da hostilidade contra os judeus. Contudo, diz Sorj,

[...] a Europa vem assistindo, desde o início do século XXI, a uma onda de manifestações antijudaicas impulsionada pelo conflito entre Israel e os palestinos. $\mathrm{O}$ entendimento desse fenômeno, tratado pelos estudiosos como um "novo antisemitismo", é muitas vezes afetado pela carga emotiva, ideológica e política que envolve o debate. Duas visões, igualmente extremadas, mostram-se insatisfatórias: aquela que minimiza o fenômeno, atribuindo-lhe caráter meramente episódico e inconsequente, que decorreria dos confrontos legítimos no contexto do conflito israelo-palestino, e a que superdimensiona o enraizamento do anti-semitismo ao estabelecer relação de simples continuidade com o passado, atualizando a narrativa do "eterno anti-semitismo". Trivializações e excessos à parte, o fato é que nos últimos anos o problema do anti-semitismo entrou no debate público europeu, mobilizando governos de diferentes países, organizações internacionais, institutos de pesquisa, organizações não governamentais, academia e estimulando um amplo debate sobre o que passou a ser conceituado como "novo anti-semitismo". (SORJ, 2007, p. 01).

Por outro lado, a crítica da religião levada a cabo no século XIX que parecia aniquilar ou, pelo menos, deslocar o fenômeno religioso para a esfera do privado, retirando dele a efetividade de força social, viu florescer a partir do pós-guerra o interesse pela compreensão do fenômeno religioso, evidenciando a vitalidade da religião. Segundo Filoramo e Prandi 
(2003. p. 5), "nunca como hoje a religião foi objeto de tantos estudos, por parte das mais variadas (do ponto de vista metodológico) disciplinas".

Ademais, se para as ciências da religião a observação da expansão do fenômeno religioso instaura a demanda de exigências metodológicas a partir das quais o estatuto de cientificidade de sua abordagem seja garantido, para a filosofia é preciso compreender não a mera expansão e multiplicação das mais diversificadas tendências religiosas, mas a "força do apelo religioso para, nos dias de hoje, mobilizar política e militarmente milhões de pessoas em todo o planeta" (CHAUI, 2004, p. 94). A autora acentua a importância de se entender a relação entre política e religião, sobretudo quando dessa relação surge "a determinação da figura religiosa do inimigo, graças à dissimulação teológico-política da guerra geopolítica de ocupação norte-americana dos territórios petrolíferos, do Afeganistão ao Golfo Pérsico, como luta do bem contra o mal" (CHAUI, 2004, p. 132). Trata-se, pois, de desvelar as nuanças do suposto amálgama entre religião e política. É nesse sentido que se reivindica a atualidade do Tratado teológico-político de Espinosa (2008) e, na sua esteira, reivindica-se também a autonomia da política em relação à religião.

\section{O LUGAR DO TRATADO TEOLÓGICO-POLÍTICO NO CONJUNTO DAS OBRAS}

Investigar ordenadamente as coisas é a pretensão do intelecto. Nesse sentido, o intelecto se apresenta como força interna para produzir ideias verdadeiras. Almejando ideias claras e distintas, Espinosa (1966, p. 91) afirma que é preciso atingir "ideias que venham do puro pensamento e que não sejam produzidas por movimentos fortuitos do corpo". A ideia verdadeira, na medida em que é índice de si mesma, permite deduzir todas as propriedades da coisa da qual é a gênese produtora. Ela exprime os nexos internos do real. Ela é aquilo que Espinosa denomina de verdade ou index sui.

$\mathrm{Na}$ superação, pois, da desordem imaginativa por um intelecto que encontra sua efetividade no encadeamento das ideias, emerge a noção de ordem como a condição sem a qual não pode haver conhecimento e, consequentemente, discurso acerca da realidade - mas não como saciedade de um desejo místico pelo florescimento da razão como quer Guéroult (1974). Nesse sentido, a concatenação das nossas representações, isto é, a organização das ideias segundo a ordem causal necessária é a correção da nossa mente ou o pensamento que pensa ordenadamente cuja expressão acabada é o discurso à maneira dos geômetras como impõe a Ética (ESPINOSA, 1979a). 
Mas a demonstração da ideia de Deus, coração da metafísica espinosana na parte I da Ética, exigiu ao fim e ao cabo um apêndice. Observa Joaquim de Carvalho (1979a, nota 162) que, para muitos, "é prova da insuficiência do método more geométrico para cabal exposição do pensamento filosófico".

Embora Carvalho não discuta a pertinência dessa opinião, não parece exagero acreditar que o "Apêndice" funciona como uma espécie de reparo, como o confirma o próprio Espinosa no segundo parágrafo do referido texto:

[...] tive o cuidado, onde quer que se me desse ocasião, de remover os prejuízos que poderiam estorvar a aceitação das minhas demonstrações, mas como ainda restam bastantes que, também, ou melhor, principalmente, poderiam e podem impedir os homens de abranger o encadeamento das coisas tal como expliquei, fui levado a pensar na conveniência de aqui os citar perante o tribunal da Razão. (ESPINOSA, 1979a, p. 116).

O "Apêndice" enfatiza o preconceito próprio da experiência vaga, palco dos encontros fortuitos, no qual o mundo aparece como contingente, o que implica, por outro lado, a representação do sujeito livre para interferir na natureza. A causalidade pressuposta, neste caso, é a eficiente transitiva, isto é, a causa que produz um efeito e se separa dele, formando dois seres independentes. $\mathrm{Na}$ incapacidade de compreender o engendramento necessário da realidade, a natureza é fantasiada como uma obra caprichosamente criada e ordenada por Deus.

O "Apêndice" é, a rigor, a retomada da crítica e recusa da concepção imaginária do infinito fundada na inversão do movimento proposto pelos axiomas III (De uma determinada causa segue-se necessariamente um efeito; se não existir qualquer causa determinada, é impossível seguir-se um efeito) e IV (O conhecimento do efeito depende do conhecimento da causa e envolve-o) da Parte I da Ética. Ou seja, parte do efeito em direção à causa. É nesse sentido que a imagem do mundo é posta como resultante do processo imaginativo, o qual se inicia com a imagem do homem, passando pela imagem do mundo, até chegar à imagem divina.

Mas, compreender Deus e não imaginá-lo é tarefa para o intelecto. O conceito de infinito só pode ser posto, pois, através do pensamento reordenado, para o qual a totalidade do real é apresentada sob a causalidade eficiente imanente. Por isso, o homem espinosano não é um poder transgressor e perturbador da ordem natural. É por ignorância que o homem é imaginado como um poder rival ao da natureza. Ele é um modo finito da substância absolutamente infinita que é Deus e, enquanto tal, parte da natureza. Está, pois, em jogo no 
"Apêndice" a retomada do argumento acerca do imanentismo e a antecipação da problemática da liberdade no âmbito modal, isto é, a liberdade - tema das quarta e quinta partes da Ética.

O tema do finalismo que o "Apêndice" põe à baila não é uma questão periférica no pensamento de Espinosa. Ao contrário, trata-se de um problema central, na medida em que tem dividido muitos intérpretes.

O centro de gravidade da questão acerca do finalismo tem sido apresentado por muitos como sendo o "Apêndice" da parte I da Ética. Gleizer (2006), por exemplo, ao analisar o referido texto afirma que Espinosa não assinala nenhuma incompatibilidade entre a tese do determinismo causal e a descrição teleológica do comportamento humano. Apoiando-se, de certa forma, nos argumentos de Curley (1990) e Garrett (1996), aquele autor se opõe à interpretação necessitarista de Guéroult (1974) e Bennett (1990), para os quais não é possível em Espinosa a compatibilidade entre a recusa da imagem finalista de Deus ou Natureza e a legitimidade de explicações teleológicas do comportamento dos entes finitos. O que está em jogo entre esses dois grupos de intérpretes é, assim, a distinção entre o finalismo da Natureza e o finalismo próprio das ações humanas. E o cenário textual levado em consideração é rigorosamente a Ética. Mas será a Ética suficiente para a solução do problema que ela mesma estabelece?

Depois da longa exposição geométrica da passagem da imagem para a ideia de Deus com todas as suas implicações, o filósofo parece não estar convencido da suficiência dessa exposição; afinal, qual é a razão que justifica o "Apêndice"? As respostas podem ser múltiplas, mas nenhuma delas pode negar que a discussão posta nele parece permitir a Espinosa a continuidade da exposição geométrica - como a breve referência ao finalismo no início da Parte III da Ética o sugere. Mas curiosamente o tema reaparece quase como uma inflexão.

A inflexão à qual nos referimos é a interrupção - ou até uma ruptura - da Ética no final da Parte III. De acordo com Aurélio (2008, p. XXI) "há, com certeza, uma ruptura e não apenas uma interrupção neste momento da obra. Mas é uma ruptura cujo alcance se tem de considerar como reinvestindo a metafísica de Espinosa de uma nova problemática e, só nessa medida, de um novo 'ponto de vista'. É precisamente esta a operação que tem lugar no Tratado teológico-político [...]".

Interrupção ou ruptura, não se pode negar que de fato o projeto do more geométrico entra em repouso ao mesmo tempo em que o Tratado teológico-político é elaborado. $\mathrm{O}$ interstício é tão evidente que Negri (1993) afirma haver dois fundamentos na Ética. Mas se 
negar a interrupção da "demonstração à maneira dos geômetras" é ignorar uma evidência, aceitar dois fundamentos pode ser uma hipótese cara demais. Por isso, na esteira de Aurélio, assumimos o vínculo entre a interrupção da Ética e a produção do Tratado teológico-político.

Situar, pois, a elaboração do Tratado na passagem para uma temática de natureza prática levada a cabo pela Ética não parece ser algo destituído de plausibilidade. Com efeito, a partir da Parte IV da Ética temos a "discussão" acerca da servidão e da liberdade humanas. Assim, não é forçoso pensar que o Tratado teológico-político ocupa um lugar central no pensamento espinosano. Diz Aurélio na segunda edição da tradução dessa obra:

\begin{abstract}
Ninguém, a bem dizer, já hoje contesta que a religião e a política de que fala aqui [TTP] estão intimamente conectadas com a filosofia demonstrada na Ética. E, no entanto, dizer isso ainda não é tudo. Porque o Tratado Teológico-Político não é apenas uma obra que tenha subjacente a concepção da realidade reivindicada pelo autor ou que para ela remeta, como teria irremediavelmente de acontecer: é, sim, a primeira e, em muitos aspectos, definitiva explanação do sistema espinosista, a tentativa programada de recuperar o que a racionalidade em moldes 'geométricos' insinuava como desordem ou servidão a resgatar pela liberdade intelectual, sem suspeitar que é precisamente aí que se decide toda a gama de possibilidades de interação dessas partículas do todo que são os homens. (AURÉLIO, 2008, p. XI).
\end{abstract}

A ênfase no Tratado teológico-político como o centro de gravidade ou, com quer Aurélio, a "definitiva explanação do sistema espinosista", longe de concebê-lo como o liame que explica a conclusão da Ética depois de cinco anos após a publicação do Tratado, parece estabelecer a liberdade no sentido político, isto é, a interação das partículas do todo (os seres humanos).

\title{
2 A TESE PRINCIPAL DO TRATADO TEOLÓGICO-POLÍTICO
}

A crítica da religião levada a cabo pelo Tratado teológico-político pretende grosso modo denunciar o caráter político da religião e os seus fundamentos. Trata-se da exposição da gênese do Estado dos hebreus como forma paradigmática da relação entre teologia e política. Nesse sentido, explicita Aurélio (2008, p. XIII):

Mas a separação que o Tratado defende não é de natureza estratégia, é de natureza política. Como tal, a análise de Espinosa não pode passar à margem do Livro em que se fundamentam as leis. Pelo contrário, se a Bíblia é a principal fonte de legitimação do poder, e, se o poder se destina a garantir a segurança e a paz entre os indivíduos, há que explicar por que razão estes se combatem em nome da mesma Bíblia, tornando assim ineficaz a suposta legitimação. Só depois disso é que se poderão 
sugerir outros fundamentos do poder, os quais implicam, já o veremos, a separação dos domínios do saber e da fé como condição para a paz e a unidade dos Estados.

Mas, para além da análise da relação religião e Estado, o Tratado teológico-político guarda uma preciosa discussão acerca do exercício da liberdade humana como fora ressaltado no Prefácio. Por isso, o filósofo procura mostrar que a liberdade não é só compatível com a vida numa república, mas é, a rigor, a condição de possibilidade da paz social. Para tanto, seria preciso, como admite Espinosa, apontar os maiores preconceitos em matéria religiosa. $\mathrm{E}$ o maior preconceito é a representação imaginária de Deus.

Da passagem da imagem para a ideia de Deus resultaria a libertação da política das amarras da teologia, enquanto espaço para o exercício das liberdades individuais. Mas essa passagem poderia muito bem ser pensada somente na Ética, o que geraria a compreensão da discussão gnosiológica sobre a qual a autonomia do político parece repousar como mera aplicação da gnosiologia apresentada no Tratado da reforma da inteligência (1966) e na Parte II da Ética (1979a).

Para a esmagadora maioria dos estudiosos do pensamento de Espinosa parece fora de questão a aceitação da Ética demonstrada à maneira dos geômetras como a obra mais elaborada e mais acabada da filosofia espinosana. De fato, não é difícil perceber que o mos geometricus é a forma mais acabada de discurso, sobretudo porque o intelecto já corrigido possibilita operações mentais no registro puramente conceitual. Quer dizer que, livre da imaginação ou do conhecimento inadequado, a verdade intelectual, enquanto índice de si mesma, pode se manifestar.

Mas era preciso transportar - e é o que Espinosa faz - a exigência gnosiológica plasmada na distinção entre imaginação e intelecto para criticar de dentro a fonte do finalismo. Tal exigência impõe ao filósofo o comprometimento do livre exercício da razão e, simultaneamente, a denúncia ao desprezo e à condenação da luz natural como fonte de impiedade. Com efeito, esse seria, talvez, o primeiro cuidado para não permitir que as invenções humanas se passem por documentos divinos, e a crendice por fé.

A decisão de investigar a Escritura sob a exigência da clareza toma como ponto de partida a pergunta "O que é profecia?" e, na esteira dela, "Como Deus se revelou aos profetas?" e "Por que foram eles escolhidos por Deus?". Da discussão inicial acerca do estatuto da profecia, Espinosa conclui que "a autoridade dos profetas só tem algum peso no que diz respeito à vida prática" (ESPINOSA, 2008, p. 11), nas circunstâncias e especificidades de uma cultura. De modo que as leis reveladas por Deus a Moisés não eram 
senão o direito particular do Estado Hebraico, isto é, dizem respeito somente aos judeus e somente enquanto durasse o referido Estado. Por outro lado, o filósofo afirma não ter encontrado naquilo que a Escritura expressamente ensina nada que fosse contrário ou estivesse de acordo com o entendimento, de tal maneira que não seria forçoso concluir que o texto sagrado "deixa a razão em absoluta liberdade e não tem nada de comum com a filosofia, assentando, pelo contrário, cada uma delas nas suas bases" (ESPINOSA, 2008, p. 12).

A conclusão que realça a separação entre texto sagrado - um texto de natureza hieróglifa - e discurso racional reverbera uma série de outras distinções, a saber, a distinção entre religião e filosofia, entre profeta e filósofo, entre moral e ética e entre teologia e política sob a distinção protocolar entre imaginação e intelecto. E a explicitação dessas distinções faz emergir a lógica do poder fundada na exclusividade de legislar, de interpretar e de aplicar as leis. Trata-se, a rigor, da recusa de qualquer fundamentação divina para o ato de legislar e para o que dele resulta. Diz Espinosa:

[...] a eleição dos judeus não tinha a ver senão com a liberdade e a felicidade temporal; quer dizer, com o Estado, com o modo e os meios através dos quais eles o conseguiram, com as leis, na medida em que eram necessárias para a estabilidade desse Estado particular, e, com a maneira, enfim, como essas foram reveladas. Quanto às outras coisas, aquelas em que consiste a verdadeira felicidade do homem, eles foram iguais aos outros. (ESPINOSA, 2008, p. 56).

Por seu lado, no Capítulo IV (sobre a Lei Divina), o filósofo procura demonstrar que

Deus só é descrito como legislador ou como príncipe e apelidado de justo, misericordioso, etc., em virtude da maneira de entender do vulgo e pela sua falta de conhecimentos. $\mathrm{Na}$ realidade, Deus age e dirige todas as coisas unicamente pela necessidade da sua natureza e perfeição: os seus decretos, enfim, e as suas volições são verdades eternas e implicam sempre uma necessidade. (ESPINOSA, 2008, p. 76).

Assim, significa que as verdades eternas e necessárias da natureza divina, na especificidade dos modos humanos, se expressam como conatus ou o direito natural de ser sui juris.

A lei divina é, sob o intelecto corrigido, o mesmo que direito natural. E esse, por sua vez, encontra a condição de possibilidade de sua realização na democracia. De modo que no Capítulo XVI do Tratado teológico-político (Dos fundamentos do Estado, do direito natural e civil de cada indivíduo e do direito dos soberanos), a democracia é apresentada como o mais natural dos regimes e, na esteira dessa apresentação, Espinosa explicita os fundamentos e o 
direito do Estado. Nesse contexto, importa ressaltar, o filósofo expõe o que ele entende por direito civil, justiça, aliados e inimigos, bem como o crime de lesa-majestade. Destes, importa destacar o seguinte:

\begin{abstract}
Inimigo, por sua vez, é aquele que vive fora do Estado, no sentido em que, nem como aliado, nem como súdito, reconhece a sua autoridade. Não é, com efeito, o ódio que faz o inimigo do Estado, mas sim o direito, sendo que o direito que tem o Estado sobre aquele que não reconhece a sua autoridade através de nenhum tipo de contrato é igual o que ele possui sobre aquele que lhe causou danos: está, portanto, no direito de obrigar, por todos os meios de que disponha, a submeter-se-lhe ou a ser seu aliado. (ESPINOSA, 2008, p. 244).
\end{abstract}

Inferir-se daqui que o não reconhecimento da autoridade soberana plasmada no direito civil pode ser considerado um ato inimigo.

Ao longo do Capítulo III do Tratado teológico-Político intitulado "Da vocação dos hebreus e se o dom da profecia terá sido um privilégio exclusivamente seu", Espinosa defende, pois, que a eleição dos judeus se deu em função do Estado - um Estado particular - e sua duração coincide precisamente com a duração do Estado. Mais do que isso, se a ideia de nação hebraica ou ao menos os sentimentos de nação permanecem é porque a identidade e sobrevivência dos judeus, a despeito da ausência de um Estado, foi mantida a expensas do ódio por eles granjeado entre as nações - o ódio que os mantém como povo.

A partir da aproximação entre o conceito de inimigo e a pretensa eleição dos judeus, parece não ser forçosa a sugestão de que a assimilação seria uma exigência do direito natural expressa na compreensão racional da política.

\title{
3 DIREITO NATURAL E DEMOCRACIA
}

A compreensão efetiva das relações intersubjetivas nos conduz ao domínio da política. Ou seja, a política plasma o campo de forças flutuantes das paixões. Segundo Chauí (2003, p.143), “é aqui, nesse campo imaginário e afetivo, nesse espaço passional, que nasce e transcorre a vida política, pois, por natureza, os homens não são avessos ao amor e ódio, à amizade e à cólera [...]". Infere-se daqui que é da natureza humana que as relações de poder devem ser deduzidas. Ora, por natureza o homem deseja governar, na mesma medida em que não deseja ser governado, de tal maneira que o direito de se manter sob seu próprio poder (sui juris) se inscreve, então, como direito natural. Por direito natural - é de suma importância explicitar - diz Espinosa: 
Por direito e instituição natural entendo unicamente as regras da natureza de cada indivíduo, regras segundo as quais concebemos qualquer ser como naturalmente determinado a existir e a agir de uma certa maneira. [...] É, com efeito, evidente que a natureza, considerada em absoluto, tem direito a tudo o que está em seu poder, isto é, o direito da natureza estende-se até onde se estende a sua potência, pois a potência da natureza é a própria potência de Deus, o qual tem pleno direito a tudo. Visto, porém, que a potência universal de toda a natureza não é mais do que a potência de todos os indivíduos em conjunto, segue-se que cada indivíduo tem pleno direito a tudo o que está em seu poder, ou seja, o direito de cada um estende-se até onde se estende a sua exata potência. (ESPINOSA, 2008, p. 235).

Todavia, o direito natural como o direito de ser sui juris é incompatível com alterirus juris, de modo que a sociabilidade é impossível no estado de natureza. Quer dizer que o direito natural ou conatus não pode realizar-se, a não ser como esforço para indagar sobre o que é mais útil, isto é, sobre qual é a melhor forma de vida, cuja resposta se inscreve como expectativa de uma coalizão de conatus sob a figura da multitudo.

A instituição da multitudo com base na cooperação é a forma de associar - pela espontaneidade do esforço de perseverar ser - potências individuais que no estado de natureza estariam sob permanente oposição. Por isso Espinosa diz que em tal estado o direito natural é nulo.

Como (consoante o $§ 9$ deste capítulo) no estado natural cada um é senhor de si próprio, enquanto pode defender-se de forma a não sofrer a opressão de outrem, e porque, individualmente, o esforço de autodefesa se torna ineficaz sempre que o direito natural humano for determinado pelo poder de cada um, tal direito será na realidade inexistente, ou pelo menos só terá uma existência puramente teórica, porquanto não há meio seguro de o conservar. (ESPINOSA, 1979c, §15, p. 312).

Enquanto multitudo, o direito de ser sui juris não só se torna possível como pode ser exponencialmente aumentado. É preciso, no entanto, que a consciência da utilidade que engendra uma espécie de pacto de cooperação sob o qual a multitudo se manifesta também compreenda a necessidade de transferência à coletividade o direito de dirimir conflitos e de empregar meios coercitivos a fim de que haja observância das leis. O problema é que se não houver a decisão das potências individuais de delegar à potência coletiva o direito de coação, a efetividade da cooperação pode ser abalada.

A potência coletiva como sujeito político ou sociedade civil - e não se trata de discutir imediatamente nos limites deste artigo as especificidades da instituição do corpo político no Tratado teológico-político e na Ética - possui o direito soberano (imperium) até onde vai sua força. Sendo o pacto uma transferência de potência, isto é, o indivíduo une o seu conatus à 
potência dos outros indivíduos pela mediação de uma espécie de duplo axioma universal, a saber, um bem só é abandonado na esperança de um bem maior ou pelo temor de um mal maior; e entre dois bens é sempre preferível o maior, assim como entre dois males é sempre preferível o menor; as ameaças à permanência do pacto é uma ameaça ao direito natural expresso na figura da multitudo. O que está em jogo aqui é a descoberta da democracia como o melhor regime, na medida em que é o mais útil e o mais natural. Diz o filósofo: "Se preferi falar dele [Estado democrático] em vez de falar de outros, é porque me parece o mais natural e o que mais se aproxima da liberdade que a natureza reconhece a cada um." (ESPINOSA, 2008, p. 242).

Afora isso, a democracia como o mais natural dos regimes é aquele que não só permite, mas expressa a efetividade do direito natural, embora a noção de representação seja opaca porque contraria o caráter intransferível da potência natural. Por isso, o exercício do poder na democracia de Espinosa aparece apenas como o direito de participação no poder, já que o imperium é intransferível. Embora cada cidadão seja, de um só golpe, legislador, governante e súdito, a potência da multitudo (direito civil) ultrapassa ou deve ultrapassar sempre a potência de cada um ou a soma das potências individuais.

O direito civil é, assim, o direito natural da multitudo. Mas não se trata de equivalência nominal pura e simplesmente. Trata-se da determinação intrínseca do campo político. Ou seja, o direito natural determina a proporcionalidade nas relações entre os cidadãos e o poder regulação expressa em termos de direito civil - e, nessa medida, impede a identificação entre governante e poder (imperium) e, finalmente, é a garantia punitiva do risco de manifestação excessiva - sempre presente porque natural - do direito natural individual, isto é, governar e não ser governado. Nesse sentido, afirma Chauí (2003, p. 172) que Espinosa insiste que "o maior inimigo do corpo político jamais é externo, mas interno a ele: é o particular ou um grupo de particulares que, a pretexto de defender e proteger as leis, aumente suas forças a ponto de tomar para si o poder e com ele identificar-se".

A ameaça interna à realização das liberdades individuais no campo político exige do direito natural o lugar de guardião. Mas se o risco é interno e natural, por que razão a demonstração do direito natural como democracia é levada a cabo a partir da análise interna da relação entre teologia e política no judaísmo? Que tipo ou grau de incompatibilidade haveria entre judaísmo e democracia ou direito natural que justificaria sua escolha como o palco da demonstração espinosana do melhor regime (o mais natural dos regimes)? 
O problema que se pretende aqui delinear diz respeito às razões pelas quais o judaísmo se presta às exigências epistemológicas e ontológicas da demonstração da autonomia da esfera política fundado no direito da natureza. Ora, se para Espinosa o político plasma o campo de forças engendrado pela consciência (exigência gnosiológica) da isonomia (exigência ontológica) entre as partes que compõem o todo, e quaisquer ameaças viriam da exacerbação das potências individuais, em que medida a escolha do judaísmo se justifica?

A pergunta acerca das razões que justificam a eleição do judaísmo como demonstração do direito natural como democracia é, pois, a discussão a partir da qual nossa hipótese emerge, qual seja, a de que tal demonstração produziria consequências antissemitas.

A recusa da política fundada em um poder transcendente exige o estabelecimento do fundamento natural para o campo político, a saber, o direito natural. Ora, a isonomia das potências individuais condensadas na figura do direito natural da multitudo - como anteriormente referido - recusa qualquer representação especial individual ou de grupos de indivíduos.

O princípio da igualdade - tão caro à democracia - tem de ser natural. Da igualdade natural é que seria possível pensar a diferenciação, desde que esta não ponha em risco o imperium. Mas, no judaísmo - segundo sugere Espinosa - a diferença é reivindicada a partir de uma visão legal de mundo. Ou seja, o judaísmo é portador de uma lógica política ameaçadora da democracia, na medida em que a ideia de nação eleita funda-se num princípio legal no qual está implicada a liberdade humana em face à natureza. Trata-se daquilo que Espinosa, desde o Apêndice da Parte I da Ética, procura combater.

Ademais, no Tratado teológico-político, se o filósofo quer demonstrar que a política é o exercício que emerge da natureza como direito natural, o judaísmo parece ser, então, sua principal antítese. Por outro lado, o direito de representar se funda na lei, mas a lei que funda o direito de representar exclui a legitimidade da representação, pois a lei que põe o profeta como legislador não é produto de uma distribuição natural do poder como expressão da liberdade e do poder da coletividade. Ou seja, o povo transfere para o profeta o poder de legislar, legitimando a lei pela mediação daquele que legisla. Em que pese a círculo vicioso, o que mais importa a Espinosa não é quem governa, mas o fundamento sobre o qual o governo se dá, sendo este melhor oferecido no Estado democrático.

A democracia espinosana, fundada no direito natural, carrega, no entanto, o spectrum da ameaça própria de um campo de forças regido pelas paixões. Ela (a ameaça) não só se manifesta lado a lado com o direito natural como, ao fazê-lo, o impossibilita, já que no estado 
de natureza o conatus não é mais do que constatação da necessidade de engendramento da multitudo.

A sombra de Estado hebreu que o judaísmo vela sob uma identidade marcada simbólica e fisicamente - como é o caso da circuncisão - reivindica a exclusividade de um imperium dentro de um imperium.

Ora, como o direito civil, em semelhantes condições, seria sistematicamente violado, resulta que ao soberano, a quem exclusivamente incumbe, quer por direito divino quer por direito natural, conservar e defender os direitos do Estado, compete o supremo direito de determinar o que entender em matéria de religião. (ESPINOSA, 2008, p. 248-249).

O referido trecho sugere, no entanto, o contrário da liberdade de expressão que se espera na democracia. Mas o que Espinosa quer, a rigor, é que a religião e a moral migrem para o seu lugar de origem, isto é, para a particularidade de uma configuração cultural circunstancial, como o exemplifica o Estado hebreu. No caso específico dos judeus não restaria senão a assimilação.

\section{CONSIDERAÇÕES FINAIS}

A defesa da assimilação inferida daqui é para Léon Poliakov (2003), autor de diversas obras sobre o antissemitismo publicadas ao longo do século XX, o motivo decisivo para afirmar que poucos homens na história das ideias contribuíram tanto como Espinosa para legitimar a perseguição aos judeus. Está claro, pois, que o que se afirma não é a atribuição de antissemitismo a Espinosa, mas implicações antissemitas na defesa da democracia como o mais natural dos regimes.

Para corroborar tal ideia, é de crucial importância a referência a Léo Strauss. Segundo este,

Espinosa reclamou haver provado, baseando-se na Bíblia, que a lei mosaica era obrigatória somente durante o período de existência do Estado judeu. Se considerarmos esses dois fatos - que a religião do Estado, de entrada, seja neutra a respeito das diferenças entre cristianismo e judaísmo e, em segundo lugar, que a lei mosaica já seria prescritiva - estaremos autorizados a dizer que Espinosa fixou as bases para outra solução puramente política do problema judeu: a alternativa ao sionismo político, a saber, a assimilação. (STRAUSS, 2004, p. 155). 
Ora, como já exposto, Espinosa afirma que o judeu não assimilado é responsável por granjear o ódio das nações. E que tal ódio teria nutrido a identidade de uma nação sem Estado. Mas Strauss argumenta que, embora Espinosa não fora hostil aos judeus, ele adquiriu uma estranha neutralidade em relação ao conflito secular entre cristianismo e judaísmo. Essa neutralidade, que para Strauss subjaz à democracia liberal defendida por Espinosa, é o móbil da propositura de assimilação e, a partir desta, o sofrimento judeu se mostra vazio de sentido. "O judeu desarraigado, assimilado, não tem nada que opor ao ódio e ao menosprezo que não seja seu eu desnudo. [...] A assimilação demonstrou exigir a escravidão interior como pagamento pela liberdade exterior.” (STRAUSS, 2004, p. 156).

Assim, ainda que do argumento de Strauss não se possa concluir mais do que a sugestão de uma espécie de antissemitismo nuançado na assimilação e que é muito inferir um antissemitismo de Espinosa, não é demais pensar que sua demonstração do direito natural como democracia pelo menos potencializaria posturas antissemitas. Uma abordagem do ponto de vista histórico merecia, no entanto, a atenção - embora escape às pretensões levadas a cabo nesta ocasião -, assim como uma detida investigação sobre as influências e apropriações do pensamento espinosano no período nazista. De todo modo, não é forçoso concluir que entre a assimilação e o sionismo muito pode ser pensado acerca de Espinosa e, sobretudo, do Espinosa de Strauss.

\section{REFERÊNCIAS}

AURÉLIO, Diogo Pires. Introdução. In: ESPINOSA, Baruch de. Tratado teológico-político. Tradução, introdução e notas Diogo Pires Aurélio. São Paulo: Martins Fontes, 2008. p. XICXXI.

AURÉLIO, Diogo Pires. Notas. In: ESPINOSA, Baruch de. Tratado teológico-político. Tradução, introdução e notas Diogo Pires Aurélio. São Paulo: Martins Fontes, 2008. p. 311375 .

BENNETT, Jonathan. Spinoza and teleology: a reply to Curley. In: CURLEY, Edwin; MOREAU, Pierrre-Francçois (Ed.). Spinoza: issues and directions. Leiden: E.J. Brill, 1990. p. 53-57.

BENNETT, Jonathan. Un estudio de la Ética de Spinoza. Méxica: Fondo de Cultura Económica, 1990.

CARVALHO, Joaquim de. Notas. In: ESPINOSA, Baruch de. Ética demonstrada à maneira dos geômetras. 2. ed. Tradução e notas da Parte I de Joaquim de Carvalho, tradução das Partes II e III Joaquim Ferreira Gomes, tradução das Partes IV e V Antônio Simões. São Paulo: Abril Cultural, 1979a. p. 71-301. (Os pensadores). 
CHAUI, Marilena. O retorno do teológico-político. In: CARDOSO, Sérgio (Org.). O retorno ao republicanismo. Belo Horizonte: Editora da UFMG, 2004. p. 93-133.

CHAUI, Marilena. Política em Espinosa. São Paulo: Cia das Letras, 2003.

CURLEY, Edwin. On Bennett's Spinoza: the Issue of teleology. In: CURLEY, Edwin; MOREAU, Pierrre-Francçois (Ed.). Spinoza: issues and directions. Leiden: E.J. Brill, 1990. p. 39-52.

ESPINOSA, Baruch de. Tratado da reforma da inteligência. Tradução, introdução e notas Lívio Teixeira. São Paulo: Cia Editora Nacional, 1966.

ESPINOSA, Baruch de. Ética demonstrada à maneira dos geômetras. 2. ed. Tradução e notas da Parte I de Joaquim de Carvalho, tradução das Partes II e III Joaquim Ferreira Gomes, tradução das Partes IV e V Antônio Simões. São Paulo: Abril Cultural, 1979a. p. 71-301. (Os pensadores).

ESPINOSA, Baruch de. Pensamentos metafísicos. Tradução e notas Marilena de Souza Chauí. São Paulo: Abril Cultural, 1979b. p. 1-40. (Os pensadores).

ESPINOSA, Baruch de. Tratado político. Tradução Manuel de Castro. São Paulo: Abril Cultural, 1979c. p. 302-366. (Os pensadores).

ESPINOSA, Baruch de. Correspondência. Tradução e notas Marilena de Souza Chauí. São Paulo: Abril Cultural, 1979d. p. 367-393. (Os pensadores).

ESPINOSA, Baruch de. Tratado teológico-político. 2. ed. Tradução, introdução e notas Diogo Pires Aurélio. São Paulo: Martins Fontes, 2008.

FILORAMO, Giovanni; PRANDI, Carlo. As ciências das religiões. São Paulo: Paulus, 2003.

GARRETT, Don. The Cambridge Companion to Spinoza. Cambridge: Cambridge Press, 1996.

GLEISER, Marcos. Espinosa e a afetividade humana. Rio de Janeiro: Zahar, 2011.

GLEISER, Marcos. Primeiras considerações sobre o problema da explicação teleológica da ação humana em espinosa. Cadernos de História e Filosofia da Ciência, Campinas, Série 3, v. 16, n. 1, p. 163-198, jan.-jun. 2006.

GUÉROULT, M. Spinoza. Tomo I e II. Paris: Aubier Montaigne, 1974.

NEGRI, A. A anomalia selvagem: poder e potência em Spinoza. Rio de Janeiro: Ed. 34, 1993.

POLIAKOV, Léon. The history of anti-semitism: from the time of Christ to the Court Jews. Filadélfia: University of Pennsylvania Press, 2003. 
SORJ, Bila. Anti-semitismo na Europa hoje. Novos estudos - CEBRAP. São Paulo, n. 79, p. 97-115, nov. 2007.

STRAUSS, Léo. Progresso ou retorno? Buenos Aires: Paidós, 2004.

WALTER, Manfred. A presença de Espinosa na Alemanha durante o período do nacionalsocialismo: Espinosa como 'contra-exemplo' da influência destrutiva do judaísmo sobre o espírito alemão? Cadernos Espinosanos. São Paulo, n. 28, p.11-38, jun. 2013. 